\title{
NECESSITY OF CBCT - EXAMINATION IN ASSESSMENT OF THE SURGICAL APPROACH FOR THE EXTRACTION OF IMPACTED LOWER THIRD MOLARS
}

\author{
Albena Gencheva ${ }^{1}$, Tihomir Georgiev ${ }^{1}$, Hristina Arnautska ${ }^{2}$, Ivan Gonkov ${ }^{1}$, Petyr Chankov ${ }^{1}$, \\ Kamen Nogalchev ${ }^{3}$ \\ ${ }^{1}$ Department of Oral and Maxillofacial Surgery, Faculty of Dental Medicine, \\ Medical University of Varna \\ ${ }^{2}$ Department of Orthodontics, Faculty of Dental Medicine, Medical University of Varna \\ ${ }^{3}$ Department of Prosthetic Dental Medicine, Faculty of Dental Medicine, \\ Medical University of Varna
}

\section{ABSTRACT}

AIM: The aim of this research is to demonstrate the necessity of CBCT - examination for evaluation of the surgical approach of high-risk impacted lower third molars. As "high-risk" we defined lower third molars which have signs of proximity to the mandibular canal seen on standard panoramic radiography.

MATERIALS AND METHODS: All patients who had undergone a CT examination between September, 2015 and October, 2016 were reviewed. We included images from cone beam computed tomography made in the Department of Radiologic Diagnostics, University Medical and Dental Centre of the Medical University of Varna. The device used was Planmeca ProMax 3D Max with software for images Planmeca Romexis. We chose 100 images randomly. From these images we selected 39 images with high-risk lower third molars. We examined different signs with which we defined the exact position to the mandibular canal of 60 wisdom teeth and we managed to asses the risk of damaging the IAN during a classical odontectomy of these teeth. In the research we included the panoramic radiographs of 20 patients from these 39 cases.

RESULTS: From the examination of the CBCT images we found: 28 lower third molars where the mandibular canal runs apical and has contact; 11 where the mandibular canal runs apical in contact with the tooth and penetration of the apices of the tooth is seen; 10 where the mandibular canal runs buccal with contact; 8 where the mandibular canal runs lingual with contact; 3 where the mandibular canal runs between the roots touching one/both of them. In three of the cases we found severe deviation of the root apices.

From the examination of the panoramic radiographs we found: 5 cases with darkening of roots in the apical area; 8 with interruption of the white line (lamina dura) of the mandibular canal; 1 with diversion of the mandibular canal with/without narrowing of the mandibular canal; 6 without any of these three signs.

Address for correspondence:

Albena Gencheva

Department of Oral and Maxillofacial Surgery,

Faculty of Dental Medicine,

Medical University - Varna

84 Tzar Osvoboiditel blvd.

9000 Varna

e-mail:a_gencheva@abv.bg

Received: October 24, 2016

Accepted: December 27, 2016
CONCLUSION: The development and rapid commercialization of new technologies like CBCT allows us to have precise images and exact diagnosis of the diseases in the oral and maxillofacial area.

Our study confirmed the high diagnostic value of $\mathrm{CBCT}$ regarding to precise the position of the lower third molars to the mandibular canal and IAN. 
Albena Gencheva, Tihomir Georgiev, Hristina Arnautska et al.

This gives the clinician the opportunity to determine which lower third molars are "high-risk" teeth and to choose the best method for surgical treatment.

Keywords: cone beam computed tomography, retention, impacted lower third molar, impacted wisdom tooth, inferior alveolar nerve (IAN), damage of IAN, surgical treatment

\section{INTRODUCTION}

The retention of the third lower molars is a common problem in the daily dental practice. The incidence in the different populations is between $9.5 \%$ (1) and $25 \%$ (2). The belief is that the main reason for retention of these teeth is insufficient space in the retromolar area $(3,4)$.

Extraction of third molars is a routine procedure in maxillofacial surgery, whether for prophylactic or for orthodontic reasons. Usually there is little risk to adjacent structures, although in some cases there may be complications owing to the intimate relationship between the roots of the third molars and the mandibular canal and/or the mandibular lingual cortex. For the patient this is expressed with temporary or permanent neurological disturbances which affect the skin and mucosa of the lip and chin of the relevant side.

Panoramic imaging is the standard radiologic examination to evaluate the anatomic relationship of third molars and the IAN. Although the panoramic radiograph is a useful screening tool for assessing the anatomic relationship between third molars and the IAN, it is imperfect. The panoramic radiograph is a two-dimensional examination which shows superimposition of shadows from different bone structures and high incidence of artifacts. These are some of the reasons which show that the panoramic radiograph does not have a high value when we talk about the risk assessment of damage the IAN during surgical extraction of impacted tooth (9).

This determines the necessity to use CBCT which shows three-dimensional (3D) images of dental structures in addition to providing clear structural images with high contrast. Cone beam CT (CBCT) is a radiographic method that has been used increasingly in several areas of dentistry. CBCT provides adequate image quality associated with a lower exposure dose, fast scanning time, lower number of artefacts and real-time image analysis $(10,11)$.
The precision of the images and possibility for three-dimensional orientation proves the extreme need of CBCT examination when ahead is a surgical treatment of high-risk lower third molar. Only with this $3 \mathrm{D}$ image the exact correlation between the roots of the third molar and the mandibular canal can be determined. When it's known this correlation the surgeon can foresee the risk of damaging the IAN.

\section{AIM}

The aim of this research is to demonstrate the necessity of CBCT - examination for evaluation of the surgical approach of high-risk impacted lower third molars. As "high-risk" we defined lower third molars which have signs of proximity to the mandibular canal seen on standard panoramic radiography.

\section{MATERIALS AND METHODS}

All patients who had undergone a CT examination between September, 2015 and October, 2016 were reviewed. We included images from cone beam computed tomography made in the Department of Radiologic Diagnostics, University Medical and Dental Centre of the Medical University of Varna. The device used was Planmeca ProMax 3D Max with software for images Planmeca Romexis. We chose 100 images randomly and from them:

$\diamond 30$ CBCT images without lower third molars

$\diamond 31$ CBCT images with lower third molars without communication to the mandibular canal

$\diamond 39$ CBCT images with high-risk lower third molars

In our study we included these 39 CBCT images and examined the variations in the position to the mandibular canal of 60 lower third molars. The assessment of the position we made using the signs approved from Öhman et al. (12)

$\diamond$ The course of the mandibular canal: The course of the mandibular canal was classified as buccal, lingual, inferior, or inter-radicular. 
Necessity of CBCT - Examination in Assessment of the Surgical Approach for the Extraction of Impacted Lower Third Molars

$\diamond$ Proximity of mandibular canal and lower third molar

$\diamond$ Narrowing of the mandibular canal in the area of the apices or in the point of contact the mandibular canal shows a preserved diameter

- "Grooving" indicates the presence of concavity or invagination of the root in which the canal was situated

$\diamond$ "Hook" indicated the presence of a deviation of the root apex, completely or partially encircling the mandibular canal

$\diamond$ Proximity of the lower third molar and the cortical plate of the mandibular canal: poor contact/ contact with thinning the plate/ contact with a perforation to the canal/ no contact

For comparison we had the panoramic x-rays of 20 of these 39 patients.

\section{RESULTS}

From the examination of the CBCT images of these 39 patients we found:

$\diamond 28$ lower third molars: the mandibular canal runs apical - in the point of contact the mandibular canal shows a preserved diameter; in the point of contact the mandibular canal shows a smaller calibre and/or an interruption of the corticalization

$\diamond 11$ lower third molar: the mandibular canal runs apical in contact with the tooth and it's seen penetration of the apices of the tooth - in the point of contact the mandibular canal shows a preserved diameter/ in the point of contact the mandibular canal shows a smaller calibre and an interruption of the corticalization

- 1 third molar with severe deviation of the root apices; with penetration

$\diamond 10$ lower third molar: the mandibular canal runs buccal - in the point of contact the mandibular canal shows a preserved diameter; in the point of contact the mandibular canal shows a smaller calibre and/or an interruption of the corticalization

$\diamond 8$ lower third molars: the mandibular canal runs lingual - in the point of contact the mandibular canal shows a preserved diameter; in the point of contact the mandibular canal shows a smaller calibre and/or an interruption of the corticalization

$\diamond 3$ lower third molars: the mandibular canal runs between the roots touching one/both of them - in the point of contact the mandibular canal shows a preserved diameter; in the point of contact the mandibular canal shows a smaller calibre and/or an interruption of the corticalization - 2 third molars with severe deviation of the root apices; with penetration

We had the panoramic radiographs of $20 \mathrm{pa}-$ tients on which we found these signs of proximity of the tooth to the mandibular canal:

$\diamond 5$ cases with darkening of roots in the apical area

$\diamond 8$ cases with interruption of white line (lamina dura) of the mandibular canal

$\diamond 1$ case with diversion of the mandibular canal with/without narrowing of the mandibular canal

$\diamond 6$ cases without any of these three signs; with presence of a deviation of the root apex

\section{DISCUSSION}

The anatomical proximity of the roots of lower third molars to the mandibular canal can cause damage to the IAN during surgical extraction or odontectomy.

The extraction of the third molar is the primary cause of the permanent neurologic deficit of the inferior alveolar nerve, being even more important than implant and orthognatic surgery $(5,6)$. Other less frequent causes of IAN injury reported in literature are: local anaesthesia - IAN block; endodontic treatment of lower premolar and molar after overfilling; malignant expansive lesions; metastases; mandibular fractures; local infections; pre-prosthetic surgery $(7,8)$.

The incidence of temporary injuries ranges from $3.3 \%$ to $13 \%$ and represents the third most common complication after alveolitis and post-operative infections (13).

The incidence of permanent lesions of the IAN ranges from $0.2 \%$ to $9 \%$ (13).

Thus, the injury of the IAN represents a serious but infrequent neurologic complication in the surgery of third molars the main reason for which is the anatomic proximity of the roots to the mandibular 
Albena Gencheva, Tihomir Georgiev, Hristina Arnautska et al.

Table 1. Incidence of IAN injury after extraction of third molars (9) (Tuzi A., Di Bari R, Cicconetti A, 3D imaging reconstruction and impacted third molars: case report)

\begin{tabular}{|c|c|c|}
\hline & Temporary IAN injury & Permanent IAN injury \\
\hline Brann CR et al. 1999 & $13.0 \%$ & $1.0 \%$ \\
\hline Carmichael FA, McGowan DA, 1992 & $3.9 \%$ & $9.0 \%$ \\
\hline Gulicher D, Gerlach KL 2000 & $3.6 \%$ & $9.0 \%$ \\
\hline Kipp DP et al. 1980 & $4.5 \%$ & $1.0 \%$ \\
\hline Smith AC et al. 1997 & $5.2 \%$ & $0.2 \%$ \\
\hline Strietzel FP, Reichart PA 2002 & $3.6 \%$ & $0.9 \%$ \\
\hline Wofford DT, Miller RI, 1987 & $3.3 \%$ & \\
\hline
\end{tabular}

canal. Therefore, this correlation must be examined very well with different imaging diagnostic methods.

An imaging exam is undoubtedly an essential tool for diagnosis and surgical management because it provides valuable information about the:

$\diamond$ tooth position

$\diamond$ number and morphology of the roots

$\diamond$ relationship of the tooth to adjacent structures, especially to the mandibular canal

Studies suggest that seven specific signs observed on panoramic radiograph are reliable ways to assess the relationship between the third molar and the mandibular canal $(14,15)$.

1. darkening of roots;

2. deflection of roots;

3. narrowing of roots;

4. bifid root apex;

5. diversion of canal;

6. narrowing of canal;

7. interruption in the white line of the canal

However, the presence or absence of these radiographic signs does not always determine the possibility of injury to the inferior alveolar nerve (IAN). This indicates that a panoramic radiograph does not have a high diagnostic accuracy when used in the assessment of risk in surgical extractions of lower third molars. This determines use of CBCT for diagnostics when a complicated extraction is suspected.

CBCT is a radiographic method for examination used in different dental medicine areas.CBCT is well suited for imaging of the craniofacial area. It provides clear images of highly contrasted structures and it is extremely useful for evaluating bone $(16,17)$. The use of CBCT technology in clinical prac- tice provides a number of potential advantages for maxillofacial imaging compared with conventional CT (18-28).

$\diamond$ Reduced size of the irradiated area by collimation of the primary x-ray beam to the area of interest minimizes the radiation dose. Most CBCT units can be adjusted to scan small regions for specific diagnostic tasks.

$\diamond$ Image accuracy: The volumetric data set comprises a 3D block of smaller cuboid structures, known as voxels, each representing a specific degree of $\mathrm{x}$-ray absorption. CBCT units provide voxel resolutions that are isotropic and equal in all 3 dimensions. The size of the voxel is from $0.076 \mathrm{~mm}$ to $0.4 \mathrm{~mm}$ and this produces submillimetre resolution ranging from $0.4 \mathrm{~mm}$ to as low as $0.125 \mathrm{~mm}$ (29).

$\diamond$ Rapid scan time: Because CBCT acquires all basic images in a single rotation of $360^{\circ}$, scan time is rapid - 10-70 seconds. Although faster scanning time usually means fewer basic images from which to reconstruct the volumetric data set, motion artifacts due to subject movement are reduced.

$\diamond$ Dose reduction

$\diamond$ Display modes unique to maxillofacial imaging

$\diamond$ Reduced image artifact and low level of metal artifact, particularly in secondary reconstructions designed for viewing the teeth and jaws (18).

Many clinical studies search for the correlation between the specific signs on panoramic radiograph and the neurologic deficit of the IAN post-operative. In other studies is searched for the conformity between the signs on panoramic x-ray and the CBCT 
Necessity of CBCT - Examination in Assessment of the Surgical Approach for the Extraction of Impacted Lower Third Molars

image of the third molars and their correlation to the mandibular canal. The aim is to prove the crucial need of 3D images when there are doubts about the exact position of the third molar and its relation to the mandibular canal (30-38). In our study we found conformity between the findings and signs on panoramic radiograph and CBCT-image in 14 from 20 cases.

In the study by Gomes et al. (39) no statistically significant association was observed between the presence of the seven panoramic radiographic signs and IAN paraesthesia after third molar extractions. However, Ghaeminia et al. (29) observed that three panoramic radiographic signs were significantly associated with IAN exposure. These signs are: interruption of white line, darkening of roots and diversion of the mandibular canal. Szalma et al. (32) identified the same three signs and had the same results. Nakagawa et al. (40) prove in their study that absence of white line on panoramic radiograph was significantly associated with an increased risk of contact between the third molar and the mandibular canal respectively a high risk of damaging the IAN. According to Monaco et al. (35). CBCT should be carried out when one of the three signs on panoramic radiograph is existing.

In our study we obtained similar results. On the $\mathrm{CBCT}$ images we found communication between the third molar and the mandibular canal in all cases where on the panoramic radiograph we found: interruption of white line, darkening of roots and diversion of the mandibular canal. We found communication also in the cases in which these three signs were missing on the $\mathrm{x}$-rays.

These results determine the exceptional necessity of using CBCT for detailed diagnostics and defining the exact position of the mandibular canal of impacted third molar.

All these third molars were defined as "highrisk teeth" with direct communication with the mandibular canal and a possibility of damaging the IAN during surgical extraction.

\section{CONCLUSION}

The development and rapid commercialization of new technologies like CBCT allows us to have precise images and exact diagnosis of the diseases in the oral and maxillofacial area. The CBCT-images give the clinician figures with high spatial details which in some cases are with size below millimeters.

Our study confirmed the high diagnostic value of CBCT regarding the precise the position of the lower third molars compared to the mandibular canal and IAN. This gives the clinician the opportunity to determine which lower third molars are "highrisk" teeth and to choose the best method for surgical treatment.

\section{REFERENCES}

1. Wang Y, He D, Yang C, Wang B, Qian W. An easy way to apply orthodontic extraction for impacted lower third molar compressing to the inferior alveolar nerve. J CraniomaxillofacSurg 2012; 40: 234-7

2. HATTAB FN, ALHAIJA ES. Radiographic evaluation of mandibular third molar eruption space. Oral Surg Oral Med Oral Pathol Oral Radiol \& Endodontics. 1999 ; 88 :285-91.

3. Maglione M., Costantinides F., Bazzocchi G., Classification of impacted mandibular third molars on cone-beam CT images, J Clin Exp Dent, 2015; 7 (2): e224 - 31 .

4. Hang - Gul Kim, Jae - Hoon Lee, Analysis and evaluation of relative positions of mandibular third molar and mandibular canal impacts, J Korean Assoc Oral Maxillofac Surg 2014; 40: 278-284

5. Dodson TB. Role of computerized tomography in management of impacted mandibular third molars. N Y State Dent J, November 2005

6. Flygare L, Ohman A. Preoperative imaging procedures for lower wisdom teeth removal. Review. Clin Oral Invest 2008; 12:291-302

7. Jerjes W, Upile T, Shah P, Nhembe F et al. Risk factors associated with injury to the inferior alveolar and lingual nerves following third molar surgery. Oral Surg Oral Med Oral Pathol Oral Radiol Endod 2010; 109:335-345

8. Tolstunov L, Pogrel MA. Delayed paresthesia of inferior alveolar nerve after extraction of mandibular third molar: case report and possible etiology. J Oral Maxillofac Surg 2009; 67:1764-1766

9. Gomes AC, Vasconcelos BGE, Silva EDO, Caldas AF, Neto IVP. Sensitivity and specificity of pantomography to predict inferior alveolar nerve damage during extraction of impacted lower third molars. J Oral Maxillofac Surg 2008; 66: 256-259. 
Albena Gencheva, Tihomir Georgiev, Hristina Arnautska et al.

10. Ziegler CM, Woertche R, Brief J, Hassfeld S. Clinical indications for digital volume tomography in oral and maxillofacial surgery. Dentomaxillofac Radiol 2002; 31: 126-130.

11. Miracle AC, Mukherji SK. Cone beam CT of the head and neck, part 1: physical principles. AJNR Am J Neuroradiol 2009; 30:1088-1095.

12. Ohman A. Kivijarvi K, Blomback U, Flygarel L. Pre-operative radiographic evaluation of lower third molars with computed tomography - research. Dentomaxillofacial Radiology (2006) 35, 30-35 q 2006 The British Institute of Radiology

13. Neugebauer J, Shirani R, Mischkowski RA, Ritter L, Scheer M, Keeve E, Zoller JE. Comparison of cone beam volumetric imaging and combined plain radiographs for localization of the mandibular canal before removal of impacted lower third molars. Oral Surg Oral Med Pathol Oral Radiol End 2008; 105:633-642

14. Rood JP, Shehab BAAN. The radiological prediction of inferior alveolar nerve injury during third molar surgery. Br J Oral Maxillofac Surg 1990; 28: 20-25.

15. Blaeser BF, August MA, Donoff RB, Kaban LB, Dodson TB. Panoramic radiography risk factors for inferior alveolar nerve injury after third molar extraction. J Oral Maxillofac Surg 2003; 61: 417-421.

16. Sukovic P. Cone beam computed tomography in craniofacial imaging. Orthod Craniofac Res 2003; 6(Suppl 1):31-6.

17. Ziegler CM, Woertche R, Brief J, Hassfeld S. Clinical indications for digital volume tomography in oral and maxillofacial surgery. Dentomaxillofac Radiol 2002; 31(2):126-30.

18. Cohnen M, Kemper J, Mobes O, Pawelzik J, Modder U. Radiation dose in dental radiology. Eur Radiol 2002; 12(3):634-7.

19. Schulze D, Heiland M, Thurmann H, Adam G. Radiation exposure during midfacial imaging using 4- and 16-slice computed tomography, cone beam computed tomography systems and conventional radiography. Dentomaxillofac Radiol 2004; 33(2):83-6.

20. Heiland M, Schulze D, Rother U, Schmelzle R. Postoperative imaging of zygomaticomaxillary complex fractures using digital volume tomography. J Oral Maxillofac Surg 2004; 62(11):1387-91.

21. Mah JK, Danforth RA, Bumann A, Hatcher D. Radiation absorbed in maxillofacial imaging with a new dental computed tomography device. Oral Surg Oral Med Oral Pathol Oral Radiol Endod 2003; 96(4):508-13.

22. Ludlow JB, Davies-Ludlow LE, Brooks SL. Dosimetry of two extraoral direct digital imaging devices: NewTom cone beam CT and Orthophos Plus DS panoramic unit. Dentomaxillofac Radiol 2003; 32(4):229-34.

23. Scaf G, Lurie AG, Mosier KM, Kantor ML, Ramsby GR, Freedman ML. Dosimetry and cost of imaging osseointegrated implants with film-based and computed tomography. Oral Surg Oral Med Oral Pathol Oral Radiol Endod 1997; 83(1):41-8.

24. Dula K, Mini R, van der Stelt PF, Lambrecht JT, Schneeberger P, Buser D. Hypothetical mortality risk associated with spiral computed tomography of the maxilla and mandible. Eur J Oral Sci 1996; 104(5-6):503-10.

25. Ngan DC, Kharbanda OP, Geenty JP, Darendeliler MA. Comparison of radiation levels from computed tomography and conventional dental radiographs.Aust Orthod J 2003; 19(2):67-75.

26. White SC. 1992 assessment of radiation risk from dental radiography. Dentomaxillofac Radiol 1992; 21(3):118-26.

27. Danforth RA, Clark DE. Effective dose from radiation absorbed during a panoramic examination with a new generation machine. Oral Surg Oral Med Oral Pathol Oral Radiol Endod 2000; 89(2):236-43.

28. Gibbs SJ. Effective dose equivalent and effective dose: comparison for common projections in oral and maxillofacial radiology. Oral Surg Oral Med Oral Pathol Oral Radiol Endod 2000; 90(4):538-45.

29. Ghaeminia H, Meijer GJ, Soehardi A, Borstlap WA, Mulder J, Berge SJ. Position of the impacted third molar in relation to the mandibular canal. Diagnostic accuracy of cone beam computed tomography compared with panoramic radiography. Int J Oral Maxillofac Surg. 2009 Sep; 38(9):964-71

30. Szalma J, Lempel E, Jeges S, Szabó G, Olasz L. The prognostic value of panoramic radiography of inferior alveolar nerve damage after mandibular third molar removal: retrospective study of 400 cases. Oral Surg Oral Med Oral Pathol Oral Radiol Endod 2009;109:294-302.

31. Khan I, Rajshekhar H, Grade P, Grade KS. Correlation of panoramic radiographs and spiral CT scan in the preoperative assessment of intimacy of the 
Necessity of CBCT - Examination in Assessment of the Surgical Approach for the Extraction of Impacted Lower Third Molars

inferior alveolar nerve canal to impacted mandibular third molars. J Craniofac Surg 2011;22:566-570.

32. Szalma J, Lempel E, Jeges S, Olasz L . Darkening of third molar roots: panoramic radiographic associations with inferior alveolar nerve exposure. J Oral Maxillofac Surg 2011;69:1544-1549.

33. Blaeser BF, August MA, Donoff RB, Kaban LB, Dodson TB . Panoramic radiographic risk factors for inferior alveolar nerve injury after third molar extraction. J Oral Maxillofac Surg 2003;61:417-421.

34. Bell GW. Use of dental panoramic tomographs to predict the relation between mandibular third molar teeth and the inferior alveolar. Radiological and surgical findings, and clinical outcome. Br J Oral Maxillofac Surg2004;42:21-27.

35. Monaco G, Montevecchi M, Bonetti GA, Gatto $\mathrm{MR}$, Checchi L. Reliability of panoramic radiography in evaluating the topographic relationship between the mandibular canal and impacted third molars. J Am Dent Assoc 2004;135:312-318.

36. Mahasantipiya PM, Savage NW, Monsour PAJ, Wilson RJ. Narrowing of the dental canal in relation to the lower third molars. Dentomaxillofac Radiol 2005;34:154-163.

37. 37. Öhman A, Kivijarvi K, Blomback U, Flygare L . Pre-operative radiographic evaluation of lower third molars with computed tomography. Dentomaxillofac Radiol 2006;35:30-35.

38. Nakamori K, Fujiwara K, Miyazaki A, Tomihara K, Tsuji M, Nakai M, et al. Clinical assessment of the relationship between the third molar and the inferior alveolar canal using panoramic images and computed tomography. J Oral Maxillofac Surg 2008;66:2308-2313.

39. Gomes AC, Vasconcelos BGE, Silva EDO, Caldas AF, Neto IVP. Sensitivity and specificity of pantomography to predict inferior alveolar nerve damage during extraction of impacted lower third molars. J Oral Maxillofac Surg 2008;66:256-259.

40. Nakagawa Y, Ishii H, Nomura Y, Watanabe NY, Hoshiba D, Kobayashi K, et al.. Third molar position: reliability of panoramic radiography. J Oral Maxillofac Surg 2007;65:1303-1308. 